\title{
Improved Antioxidant Capacity and Immune Function of Broiler Chickens Fed with Selenium- enriched Candida utilis
}

-Author(s)

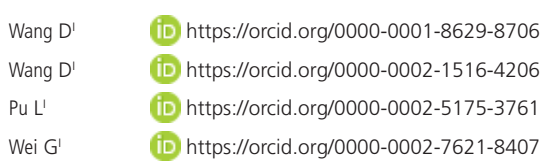

Wei Gl (iD https://orcid.org/0000-0002-7621-8407

School of Biology and Basic Medical Sciences, Soochow University, Suzhou 215123, China.

\section{nail Address}

Corresponding author e-mail address Wei Gongyuan

School of Biology and Basic Medical Sciences, Soochow University, 199\# Ren'ai Road,

Suzhou Industrial Park, Suzhou 215123, PR China.

Phone: +8651265880421

Email: weigy@suda.edu.cn

\section{- Keywords}

Antioxidant capacity; broiler chickens; glutathione; immune function; seleniumenriched Candida utilis.

\section{ABSTRACT}

The aim of this study was to assess the effect of selenium-enriched Candida utilis with high contents of organic selenium (Se) and glutathione (GSH) on growth performance, antioxidant capacity and immune function of broiler chickens. A total of 100 healthy 7-dayold male broiler chickens were randomly divided into 5 groups, and fed diets supplemented with (a) $\mathrm{Na}_{2} \mathrm{SeO}_{3}$ (b) C. utilis, (c) Se-enriched Saccharomyces cerevisiae, (d) Se-enriched C. utilis, and (e) the control without any supplements. The experiment lasted for 6 weeks and parameters were recorded on day 42 . No significant differences in average daily gain were found among the 5 groups. However, Se-enriched C. utilis supplemented in the diet increased activities of glutathione peroxidase in the whole blood $(p<0.01)$, catalase in the serum $(p<0.01)$ and breast meat $(p<0.01)$, and superoxide dismutase in the breast meat $(p<0.01)$, as well as decreased contents of malondialdehyde in the serum $(p<0.01)$, liver $(p<0.01)$ and breast meat $(p<0.05)$. Also, Seenriched $C$. utilis improved titers of $\lg G(p<0.01)$, $\lg M(p<0.01)$, and $\lg \mathrm{A}(p<0.01)$ in the serum, as compared to the control. All these results indicated that Se-enriched C. utilis was a good candidate of dietary supplement to improve the antioxidant capacity and immune function of broiler chickens.

\section{INTRODUCTION}

Selenium (Se) is an essential nutritional trace element for human beings and animals owing to its critical role in cell metabolism (Schrauzer, 2006; Kieliszek \& Błażejak, 2013). Se is now being widely studied because of its antioxidant and immunity-associated capacities in many higher eukaryotic organisms (Burk, 2002; Tapiero et al., 2003; Rayman, 2005; Hoffmann \& Berry, 2008). In broiler chickens, Se is essential for the normal function of antioxidant and immune systems, and Se deficiencies are associated with diarrhea, pancreas atrophy, reproductive dysfunction, and immune or nerve damage (Yang et al., 2016). Thus, it is necessary to ensure sufficient Se in the diet by adding Se supplements to reduce the incidences of these symptoms.

In June 2000, Se-enriched yeast was approved by the US Food and Drug Administration as a safe source of feed-supplemented organic Se for animals (Food and Drug Administration, 2000). Since then, Seenriched yeast (also known as selenized yeast) has commonly been used as a feed additive in the raising of livestock and poultry (Surai \& Fisinin, 2014; Baltić et al., 2015; Shi et al., 2017). Saccharomyces cerevisiae and Candida utilis are usually used for the preparation of Se-enriched yeast because they are capable of producing biomasses with high protein contents and can transform inorganic Se (toxic and low bioavailability) into organic Se (safer and bioactive) (Yin et al., 2010; Wang et al., 2012). In recent years, Se-enriched C. utilis 
has attracted more and more attention owing to its higher intracellular glutathione (GSH) content and higher bioconversion rate from inorganic Se to organic Se than Se-enriched S. cerevisiae (Yang et al., 2013; Kieliszek et al., 2017).

According to the literature, Se-enriched S. cerevisiae has been shown to enhance the growth performance, antioxidant capacity, and meat quality of broiler chickens (Wang \& Xu, 2008; Li et al., 2017). Moreover, organic Se from selenized $S$. cerevisiae also favored to improve the immune status of broiler chickens, and a higher titer of IgM was obtained after Se supplementation (Boostani et al., 2015). However, little is known about the effects of Se-enriched C. utilis on the raising of broiler chickens. In this study, we aimed to evaluate the effects of Se-enriched C. utilis on growth performance, antioxidant capacity, and immune function of broiler chickens. Additionally, the reason why Se-enriched $C$. utilis was more effective than other supplements in the diet was also elucidated.

\section{MATERIALS AND METHODS}

\section{Selenium sources}

Sodium selenite $\left(\mathrm{Na}_{2} \mathrm{SeO}_{3}\right)$ was purchased from Sinopharm Chemical Reagent Co., Ltd. (Shanghai, China). The commercial Se-enriched $S$. cerevisiae (2000 $\mu \mathrm{g} / \mathrm{g}$ Se and $5.0 \mathrm{mg} / \mathrm{g} \mathrm{GSH}$ ) was purchased from AngelYeast Co., Ltd. (Yichang, China). The cells of C. utilis (14.6 mg/g GSH) and Se-enriched C. utilis (1884 $\mu \mathrm{g} / \mathrm{g}$ Se and $13.1 \mathrm{mg} / \mathrm{g}$ GSH) were prepared using $\mathrm{C}$. utilis SZU 07-01 according to the methods described in our previous studies (Wang et al., 2012; Nie et al., 2010). All the yeast cells supplied to the diet were in live conditions.

\section{Experimental design and chicken trials}

In total, 100 healthy 7-day-old male white broiler chickens, with a mean initial body weight of $108 \pm 8$ $\mathrm{g}$, were purchased from a local farm in Suzhou, China. The chickens were randomly divided into 5 groups with 20 animals per group. The dietary supplements were designed as follows: group $\mathrm{A}$, inorganic $\mathrm{Se}$ of $\mathrm{Na}_{2} \mathrm{SeO}_{3}$; group B, C. utilis cells; group C, commercial Se-enriched S. cerevisiae; group D, Se-enriched C. utilis; and group $E$, the control without any supplements (Table 1). The nutrient contents of the basal chicken diet are shown in Table 2. The dose of Se in the Se-supplemented diet was maintained at $3.0 \mathrm{mg} / \mathrm{kg}$, and the dose of $C$. utilis provided to group $B$ was equivalent to that of Seenriched C. utilis provided to group D.
Table 1 - Supplements in the diet of broiler chickens.

\begin{tabular}{lcc}
\hline Description of groups & $\mathrm{Se}^{{ }^{a}}$ & $\mathrm{GSH}$ \\
\hline Group A: $\mathrm{Na}_{2} \mathrm{SeO}_{3}$ & + (inorganic Se) & - \\
Group B: $\mathrm{C}$. utilis & - & + \\
Group C: Se-enriched S. cerevisiae & + (organic Se) & + \\
Group D: Se-enriched C. utilis & + (organic Se) & + \\
Group E: control & - & - \\
\hline
\end{tabular}

+: Diet containing this composition; -: none of this component in the diet.

a The dose of Se in the diets was maintained at $3.0 \mathrm{mg} / \mathrm{kg}$.

The broiler chickens were fed for 6 weeks in stainless steel cages in an air-conditioned animal facility with a constant temperature of $27 \pm 1^{\circ} \mathrm{C}$, humidity of $50 \pm$ $5 \%$, and a 12-h light/dark cycle. The chickens were allowed free access to feed and fresh water. The body weight of the broiler chickens was determined weekly throughout the experiment, and average daily gain was calculated for each chicken. All animal procedures were performed in compliance with protocols approved by the Committee for the Care and Utilization of Experimental Animals of Soochow University.

Table 2 - Nutrient content of the basal diet *

\begin{tabular}{lc}
\hline Chemical composition & Content $(\mathrm{g} / \mathrm{kg})$ \\
\hline Water & 101.3 \\
Crude protein & 200.2 \\
Crude fat & 40.4 \\
Crude fiber & 49.8 \\
Ash & 80.7 \\
Calcium & 10.3 \\
Available phosphorus & 6.2 \\
Lysine & 13.2 \\
Methionine and cystine & 7.8 \\
\hline
\end{tabular}

"Supplied per kilogram of diet: vitamin A, 10000 IU; vitamin $D_{3^{\prime}}$ 4000 IU; vitamin K, 3 mg; vitamin $E_{1} 100 \mathrm{IU}$; vitamin $\mathrm{B}_{1}, 3.5 \mathrm{mg}$; vitamin $\mathrm{B}_{2^{\prime}} 10 \mathrm{mg}$; vitamin $\mathrm{B}_{6^{\prime}} 4 \mathrm{mg}$; vitamin $B_{12^{\prime}} 1 \mathrm{mg}$; nicotinic acid, $50 \mathrm{mg}$; pantothenic acid, $20 \mathrm{mg}$; folic acid, $2 \mathrm{mg}$; biotin, 0.2 $\mathrm{mg}$; choline, $1000 \mathrm{mg}$; manganese, $80 \mathrm{mg}$; manganese, $100 \mathrm{mg}$; iron, $80 \mathrm{mg}$; copper, $8 \mathrm{mg}$; zinc, $80 \mathrm{mg}$; and iodine, $0.35 \mathrm{mg}$.

\section{Sample collection and preparation}

At the end of the animal experiment (on day 42), the broiler chickens were sacrificed after being electrically stunned. Blood samples were collected through veins under the wings, and then divided into two portions. One portion was collected into a $10-\mathrm{mL}$ heparinized tube and centrifuged at $3,000 \mathrm{~g}$ and $4^{\circ} \mathrm{C}$ for $15 \mathrm{~min}$ to obtain serum, and another portion was collected as the whole blood, which was used to determine the contents of Se and GSH, and glutathione peroxidase (GSH-Px) activity. Both blood samples were gently ejected into $5-\mathrm{mL}$ Eppendorf tubes at $-70^{\circ} \mathrm{C}$. The breast meat samples of each carcass were individually sliced into different sections. One section was kept at 
$4^{\circ} \mathrm{C}$ for the measurement of the drip-loss rate, and the other sections were vacuum-packed in plastic bags and frozen at $-70^{\circ} \mathrm{C}$ for further analysis. The liver, thymus, spleen, and fabricius tissues were rapidly excised and rinsed with ice-cold isotonic saline, and then stored at $-70^{\circ} \mathrm{C}$ before determinations.

The contents of Se and GSH in the whole blood, breast meat, and liver samples were determined by the methods described in the previous study (Wang et al., 2012).

\section{Determination of the drip-loss rate of breast meat}

For the quantification of the drip-loss rate of breast meat, the fresh samples $(\sim 10 \mathrm{~g})$ cut from the carcass were immediately hung up in an inflated plastic bag. After storage at $4^{\circ} \mathrm{C}$ for $48 \mathrm{~h}$, the samples were weighed again. The drip-loss rate was expressed as a percentage of the reduced weight to the initial weight (Honikel, 1998).

\section{Antioxidant capacity assay}

Chicken breast meat or liver samples (1 g) were homogenized in $9 \mathrm{~mL}$ of ice-cold buffer solution (50 $\mathrm{mmol} / \mathrm{L}$ Tris and $0.5 \mathrm{mmol} / \mathrm{L}$ EDTA, $\mathrm{pH}$ 8.0) using an Ultra-Turrax homogenizer (Tekmar Co. Ltd., Cincinnati, $\mathrm{OH}$, USA) at 8,000 rpm for $10 \mathrm{~s}$ and centrifuged at $3,000 \mathrm{~g}$ and $4^{\circ} \mathrm{C}$ for $15 \mathrm{~min}$. The supernatant was used to analyze the antioxidant capacity. The GSHPx activity in the whole blood, catalase (CAT) and superoxide dismutase (SOD) activities, as well as the malondialdehyde (MDA) levels in serum, breast meat, and liver samples were assayed using appropriate commercial assay kits purchased from Nanjing Jiancheng Bioengineering Institute (Nanjing, China) in compliance with the manufacturers' instructions. The assays were conducted using spectrophotometric methods (UV2550, Shimadzu, Tokyo, Japan).

\section{Immunity assessment}

The immune organs, thymus, spleen and fabricius, of each chicken were weighed. The immune organ indices were expressed as the ratio of the weight of the immune organ (thymus, spleen, or fabricius) relative to the chicken's body weight. The titers of immunoglobulins, such as $\lg G, \lg M$, and $\lg A$, in the serum were determined by the double-antibody sandwich enzyme-linked immunosorbent assay method using commercial kits purchased from Suzhou Kechuang Biotechnology Co., Ltd. (Suzhou, China) in compliance with the manufacturers' instructions.

\section{Statistical analyses}

All values were expressed as means \pm standard deviations. The Student's $t$ test was employed to evaluate statistical significance, and samples with $p \leq 0.05$ were considered to be statistically significant. Statistical calculations were performed using SPSS 17.0 software (SPSS Inc, Chicago, IL, USA).

\section{RESULTS}

\section{Growth performance}

The growth performance of broiler chickens fed with diets containing different supplements was evaluated by comparing the average daily gain of chickens. As shown in Fig. 1A, no significant differences in average daily gain were found among the five groups. That is, the growth of chickens fed with different supplements showed similar results relative to the control.
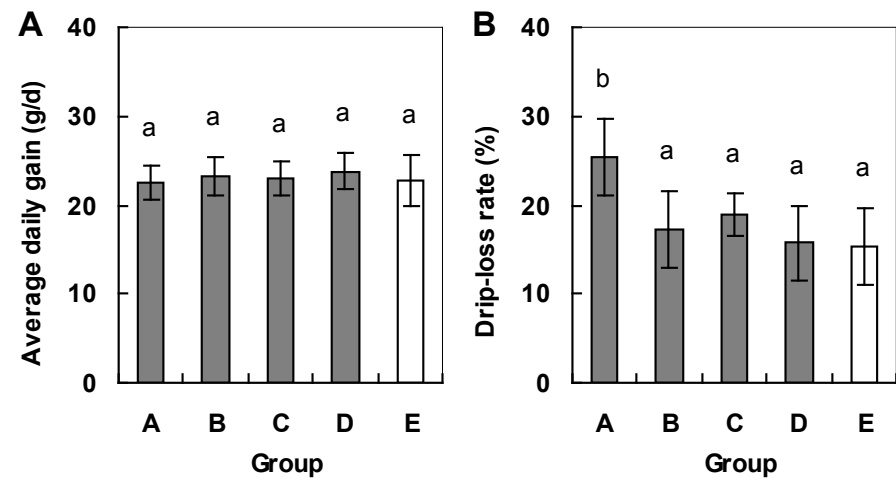

Figure 1 - The growth performance $(A)$ and drip-loss rate of the breast meat $(B)$ of broiler chickens fed with different dietary supplements of $\mathrm{Na}_{2} \mathrm{SeO}_{3}$ (group A), C. utilis (group B), Se-enriched S. cerevisiae (group C), and Se-enriched C. utilis (group D). The control (group E) represents no addition of supplement in the basal diet of broiler chickens. Bars labeled with different letters indicate significant differences $(p<0.05)$, while the same letters indicate no significant differences ( $p>0.05)$, as compared to the control.

The drip-loss rate of chicken breast meat was also determined and compared. As shown in Fig. 1B, group $A\left(\mathrm{Na}_{2} \mathrm{SeO}_{3}\right)$ showed higher drip-loss rate $(p<0.05)$ than that of the control, indicating that the waterholding capacity of breast meat decreased greatly in broiler chickens fed with inorganic Se. Chickens fed diets supplemented with yeast cells (whether selenized or not) showed no significant differences in drip-loss rate of the breast meat relative to the control.

\section{Se distribution}

Total Se contents in the whole blood, liver, and breast meat of broiler chickens were determined. As shown in Fig. 2, no changes in Se contents in whole blood, liver and meat were observed in group $B$ ( $C$. utilis cells), when compared to the control. However, the diets supplemented with either organic Se 
(group $\mathrm{C}$ and D) or inorganic Se (group $\mathrm{A}, \mathrm{Na}_{2} \mathrm{SeO}_{3}$ ) significantly increased Se contents $(p<0.05)$ in both whole blood and liver. Moreover, the Se content of the breast meat in group D (selenized C. utilis) increased by $95 \%$, as compared to the control. According to the above results, only Se-enriched $C$. utilis simultaneously improved the Se contents in whole blood $(p<0.05)$, liver $(p<0.05)$, and breast meat $(p<0.05)$ of broiler chickens.

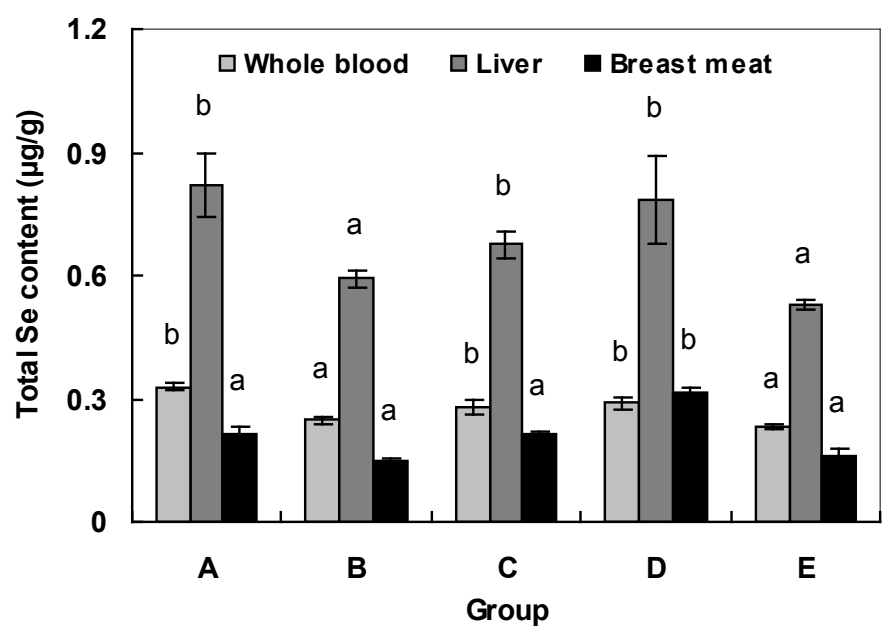

Figure 2 - Total Se content in the whole blood, liver, and breast meat of broiler chickens fed with different dietary supplements of $\mathrm{Na}_{2} \mathrm{SeO}_{3}$ (group A), C. utilis (group B), Se-enriched $S$. cerevisiae (group C), and Se-enriched C. utilis (group D). The control (group E) represents no addition of supplement in the basal diet of broiler chickens. In the same tissue, bars labeled with different letters indicate significant differences $(p<0.05)$, while the same letters indicate no significant differences $(p>0.05)$, as compared to the control.

\section{Antioxidant enzyme activities}

The effects of different dietary supplements on the activities of antioxidant enzymes, such as GSH-Px, CAT, and SOD, in blood and tissues of broiler chickens were investigated. As shown in Table 3, no obvious differences were found in the activity of GSH-Px in the whole blood between groups $\mathrm{A}\left(\mathrm{Na}_{2} \mathrm{SeO}_{3}\right), \mathrm{B}(\mathrm{C}$. utilis), $C$ (selenized $S$. cerevisiae), and the control. However, group D supplemented with Se-enriched C. utilis resulted in much higher GSH-Px activity in the whole blood, which increased by $41.7 \%(p<0.01)$ as compared to the control.

Moreover, supplements of Se and/or yeast in the diet, all increased the activity of CAT in the serum $(p<0.01)$, while had no significant effects on CAT activity in the liver. As to the CAT in the breast meat, only Se-enriched $C$. utilis resulted in an increase of $72.4 \%(p<0.01)$ in CAT activity relative to the control, other supplements showed no significant differences in CAT activity. In addition, the activities of SOD in the serum and liver of broiler chickens showed no significant differences between the control and groups fed with diverse supplements. However, the activities of SOD in the breast meat increased when adding selenized $S$. cerevisiae or selenized $C$. utilis to the diet, which increased by $23.9 \%(p<0.05)$ and $43.6 \%$ $(p<0.01)$, respectively, as compared to the control.

Table 3 - Antioxidant capacities of broiler chickens fed with different dietary supplements.

\begin{tabular}{|c|c|c|c|c|c|}
\hline Group & $A$ & B & C & D & $E$ \\
\hline Supplements & $\mathrm{Na}_{2} \mathrm{SeO}_{3}$ & C. utilis & $\begin{array}{l}\text { Se-enriched } \\
\text { S. cerevisiae }\end{array}$ & $\begin{array}{l}\text { Se-enriched } \\
\text { C. utilis }\end{array}$ & Control \\
\hline \multicolumn{6}{|l|}{ Whole blood } \\
\hline GSH-Px (U/mL) & $2672 \pm 107 a$ & $2752 \pm 378 a$ & $2512 \pm 398 a$ & $3264 \pm 164 B$ & $2304 \pm 454 a A$ \\
\hline GSH (mg/L) & $36.08 \pm 2.07 a$ & $45.57 \pm 2.93 b$ & $37.38 \pm 1.40 \mathrm{a}$ & $47.57 \pm 3.35 b$ & $39.49 \pm 3.94 a$ \\
\hline \multicolumn{6}{|l|}{ Serum } \\
\hline CAT (U/mL) & $0.70 \pm 0.04 \mathrm{~B}$ & $0.77 \pm 0.07 \mathrm{~B}$ & $0.67 \pm 0.07 \mathrm{~B}$ & $0.83 \pm 0.08 \mathrm{~B}$ & $0.51 \pm 0.04 \mathrm{~A}$ \\
\hline $\mathrm{SOD}(\mathrm{U} / \mathrm{mL})$ & $1.43 \pm 0.02 a$ & $1.42 \pm 0.05 a$ & $1.42 \pm 0.11 a$ & $1.48 \pm 0.05 a$ & $1.26 \pm 0.24 a$ \\
\hline $\mathrm{MDA}(\mathrm{nmol} / \mathrm{mL})$ & $2.34 \pm 0.21 b$ & $2.04 \pm 0.19 B$ & $2.47 \pm 0.19 b$ & $1.49 \pm 0.15 B$ & $2.77 \pm 0.21 \mathrm{aA}$ \\
\hline \multicolumn{6}{|l|}{ Liver } \\
\hline CAT (U/g) & $13.02 \pm 2.49 a$ & $13.76 \pm 1.62 a$ & $12.96 \pm 2.31 \mathrm{a}$ & $14.62 \pm 2.16 a$ & $12.61 \pm 1.62 \mathrm{a}$ \\
\hline $\mathrm{SOD}(\mathrm{U} / \mathrm{g})$ & $1.64 \pm 0.30 a$ & $1.75 \pm 0.33 a$ & $1.64 \pm 0.27 a$ & $1.90 \pm 0.29 a$ & $1.59 \pm 0.30 a$ \\
\hline MDA (nmol/g) & $0.39 \pm 0.03 a$ & $0.34 \pm 0.03 b$ & $0.36 \pm 0.02 b$ & $0.29 \pm 0.03 B$ & $0.42 \pm 0.05 \mathrm{aA}$ \\
\hline $\mathrm{GSH}(\mathrm{mg} / \mathrm{g})$ & $4.55 \pm 0.98 a$ & $5.25 \pm 0.78 b$ & $4.25 \pm 0.09 a$ & $7.19 \pm 0.92 B$ & $4.22 \pm 0.55 \mathrm{aA}$ \\
\hline \multicolumn{6}{|l|}{ Breast meat } \\
\hline CAT (U/g) & $0.23 \pm 0.09 a$ & $0.27 \pm 0.09 a$ & $0.24 \pm 0.06 a$ & $0.30 \pm 0.01 B$ & $0.18 \pm 0.08 a A$ \\
\hline $\operatorname{SOD}(\mathrm{U} / \mathrm{g})$ & $0.51 \pm 0.05 a$ & $0.52 \pm 0.08 a$ & $0.53 \pm 0.03 b$ & $0.61 \pm 0.07 \mathrm{~B}$ & $0.42 \pm 0.08 \mathrm{aA}$ \\
\hline MDA (nmol/g) & $0.04 \pm 0.01 a$ & $0.03 \pm 0.01 b$ & $0.05 \pm 0.01 a$ & $0.03 \pm 0.01 b$ & $0.05 \pm 0.01 a$ \\
\hline GSH (mg/g) & $0.18 \pm 0.02 B$ & $0.45 \pm 0.04 \mathrm{~B}$ & $0.09 \pm 0.01 \mathrm{~B}$ & $0.49 \pm 0.02 B$ & $0.07 \pm 0.01 \mathrm{~A}$ \\
\hline
\end{tabular}

$a, b, A, B$ In the same row, values with different lower-case letters indicate significant differences $(p<0.05)$, with different capital letters indicate extremely significant differences ( $p<0.01)$, while the same letters indicate no significant differences ( $p>0.05)$.

GSH-Px, glutathione peroxidase; GSH, glutathione; CAT, catalase; SOD, superoxide dismutase; MDA, malondialdehyde. 


\section{GSH and MDA contents}

The contents of GSH in the whole blood, liver, and breast meat of broiler chickens fed with different dietary supplements were determined. As shown in Table 3, groups $\mathrm{A}\left(\mathrm{Na}_{2} \mathrm{SeO}_{3}\right)$ and $\mathrm{C}$ (selenized $\mathrm{S}$. cerevisiae) showed no significant differences in GSH contents in the whole blood and liver, as compared to the control (group E). However, supplements of C. utilis (group B) and selenized C. utilis (group D) both resulted in increases in GSH contents of the whole blood and tissues. The GSH contents increased by $15.4 \%(p<0.05)$ and $20.5 \%(p<0.05)$ in the whole blood, $24.3 \%(p<0.05)$ and $70.3 \%(p<0.01)$ in the liver, and $594 \%(p<0.01)$ and $658 \%(p<0.01)$ in the breast meat, respectively, as compared to the control. Thus, the supplementation of C. utilis and Se-enriched C. utilis to the diets contributed to the accumulation of GSH in blood and tissues of broiler chickens.

The intracellular MDA contents in serum, liver, and breast meat of broiler chickens were also assayed. As shown in Table 3, MDA in the serum significantly decreased by adding all the supplements $(p<0.05$ for groups $A$ and $C ; p<0.01$ for groups $B$ and $D$ ) tested in this study, while no differences in contents of MDA in the liver were found when $\mathrm{Na}_{2} \mathrm{SeO}_{3}$ was supplemented to the diet. In addition, MDA in the breast meat only decreased in the presence of $C$. utilis $(p<0.05)$ and Seenriched $C$. utilis $(p<0.05)$, as compared to the control. According to the results shown in Table 3 , it should be noted that the greater the GSH contents obtained with supplements, the lower the MDA contents were found in serum, liver, and breast meat of chickens. The Seenriched C. utilis resulted in the lowest MDA contents in serum and tissues, indicating that broiler chickens fed with this kind of selenized yeast had much greater antioxidant capacities than those did not receive any dietary supplements.

\section{Immune functions}

The immune functions of broilers, including the immune organ (thymus, spleen, and fabricius) indices and the titers of immunoglobulins ( $\lg G, \lg \mathrm{M}$, and $\lg \mathrm{A}$ ) in serum were determined and compared in Table 4. When the broilers were fed with Se-enriched S. cerevisiae as the dietary supplement, the indices of thymus $(p<0.05)$ and fabricius $(p<0.01)$ decreased significantly, while the spleen index increased $(p<0.01)$, as compared to the control. Besides, other dietary supplements $\left(\mathrm{Na}_{2} \mathrm{SeO}_{3}, \mathrm{C}\right.$. utilis, and Se-enriched $\mathrm{C}$. utilis) showed no differences in the indices of immune organ of broiler chickens.

Moreover, the titers of $\lg G$ in the sera increased $(p<0.01)$ when the chickens were fed with Seenriched C. utilis, other supplements showed no significant differences in $\lg G$ as compared to the control. The IgM titers both increased with the addition of $C$. utilis $(p<0.01)$ and Se-enriched $C$. utilis $(p<0.01)$ but decreased with selenized $S$. cerevisiae $(p<0.01)$. Different from titers of the above two immunoglobulins, the $\lg A$ titer increased significantly $(p<0.01)$ with all the supplements in the diet. Taken together, the supplementation of Se-enriched $C$. utilis in the diet resulted in the highest titers of $\lg G$, $\operatorname{lgM}$, and IgA in the sera of broiler chickens, which increased by $17 \%(p<0.01), 18 \%(p<0.01)$, and $386 \%$ $(p<0.01)$, respectively, as compared to the control. Thus, the broiler chickens fed with Se-enriched C. utilis had greater immunity function than those fed diets containing other supplements or no supplements.

\section{DISCUSSION}

Se-enriched yeast, a well-known feed additive, has already been approved by the US Food and Drug Administration as a safe source of organic Se in animal

Table 4 - Immune functions of broiler chickens fed with different dietary supplements.

\begin{tabular}{|c|c|c|c|c|c|}
\hline Group & A & $B$ & C & $\mathrm{D}$ & $E$ \\
\hline Supplements & $\mathrm{Na}_{2} \mathrm{SeO}_{3}$ & C. utilis & $\begin{array}{l}\text { Se-enriched } \\
\text { S. cerevisiae }\end{array}$ & $\begin{array}{l}\text { Se-enriched } \\
\text { C. utilis }\end{array}$ & Control \\
\hline \multicolumn{6}{|c|}{ Immune organ index } \\
\hline Thymus (\%) & $0.29 \pm 0.07 a$ & $0.31 \pm 0.07 a$ & $0.25 \pm 0.09 b$ & $0.34 \pm 0.10 a$ & $0.32 \pm 0.08 a$ \\
\hline Spleen (\%) & $0.22 \pm 0.07 a$ & $0.21 \pm 0.04 a$ & $0.29 \pm 0.08 \mathrm{~B}$ & $0.26 \pm 0.08 a$ & $0.22 \pm 0.07 a A$ \\
\hline Fabricius (\%) & $1.10 \pm 0.14 a$ & $1.01 \pm 0.11 \mathrm{a}$ & $0.92 \pm 0.17 \mathrm{~B}$ & $1.01 \pm 0.16 a$ & $1.09 \pm 0.12 \mathrm{aA}$ \\
\hline \multicolumn{6}{|c|}{ Immunoglobulin } \\
\hline $\operatorname{lgG}(\mathrm{mg} / \mathrm{mL})$ & $5.37 \pm 0.19 a$ & $5.46 \pm 0.29 a$ & $4.99 \pm 0.30 a$ & $6.05 \pm 0.30 B$ & $5.17 \pm 0.27 \mathrm{aA}$ \\
\hline $\operatorname{lgM}(\mathrm{mg} / \mathrm{mL})$ & $0.82 \pm 0.05 a$ & $0.87 \pm 0.04 \mathrm{~B}$ & $0.72 \pm 0.03 B$ & $0.94 \pm 0.03 B$ & $0.80 \pm 0.05 \mathrm{aA}$ \\
\hline $\lg A(\mu \mathrm{g} / \mathrm{mL})$ & $29.75 \pm 2.09 B$ & $41.50 \pm 1.25 B$ & $24.75 \pm 2.59 B$ & $53.50 \pm 2.09 B$ & $11.00 \pm 1.90 \mathrm{~A}$ \\
\hline
\end{tabular}

$a, b, A, B$ In the same row, values with different lower-case letters indicate significant differences $(p<0.05)$, with different capital letters indicate extremely significant differences $(p<0.01)$, while the same letters indicate no significant differences $(p>0.05)$. 
feedstock (Food and Drug Administration, 2000; Kieliszek et al., 2015). GSH is widely distributed in yeast cells to maintain an intracellular redox environment, and a greater intracellular GSH content increases the antioxidant capacity of the yeast cells (Li et al., 2004). Hence, high Se and GSH contents are essential to increase the performance of Se-enriched yeast, which, in turn, will expand the applicability of selenized yeast (Yang et al., 013). In the present study, Se-enriched C. utilis with high intracellular organic Se and GSH contents was used as a dietary supplement for the raising of broiler chickens. The growth performance, antioxidant capacity, and immune function of broiler chickens were also evaluated with or without dietary supplements.

Se can regulate the activities of insulin-like growth hormone and thyroid hormone growth factor, and enhance the dissimilation of fat, sugar, and protein in the body, which is beneficial to energy supply and animal growth (Burk, 2002; Fairweather-Tait et al., 2011). Low dietary Se intake is associated with an increased risk in chronic diseases relating to oxidative stress (Rayman, 2000; Beck et al., 2003). In this study, Se-enriched C. utilis was supplemented to the diet of broiler chickens, and simultaneously improved Se contents in whole blood, liver, and breast meat (Fig. 2), showing greater ability of Se accumulation, which is in accordance with those obtained in goats (Zhang et al., 2018). However, no significant differences in average daily gain and driploss rate were found between groups of Se-enriched $C$. utilis and the control. As the drip-loss rate is an important index for measuring the quality of breast meat of broiler chickens (Phongpangan et al., 2014), these results indicated that Se-enriched C. utilis had no remarkable contribution to improve the quality of breast meat.

The elimination of free radicals in animal bodies depends on an enzymatic system consisting of GSHPx, CAT, and SOD, as well as a non-enzymatic system, including vitamins $\mathrm{C}$, and $\mathrm{E}$, and GSH (Galano \& Alvarezidaboy 2011). The activities of these enzymes in the serum and tissues, as well as the GSH contents in tissues, are important indices of the antioxidant capacity of the body (Gan et al., 2014). In this study, GSH-Px in the whole blood showed higher activities when Se-enriched C. utilis was supplemented to the diet, as compared to the control. Se is the vital cofactor of GSH-Px and GSH is the substrate (Arthur, 2000), therefore, the addition of Se-enriched $C$. utilis containing both Se and GSH favored to the increase in the activity of GSH-Px. CAT in the serum and breast meat, as well as SOD in the breast meat of broiler chickens fed with the Se-enriched C. utilis showed higher activities than those of the control.
Moreover, the contents of GSH in the whole blood, liver, and breast meat were also greater than that of the control. Besides, Se-enriched C. utilis resulted in the lowest MDA contents in serum, liver, and breast meat of broiler chickens. MDA, an end product of lipid peroxidation, is usually used as a cell index to indicate the severity of stress encountered (Koh et al., 2000). The reduced MDA contents in serum and tissues of broiler chickens indicated that the Se-enriched C. utilis decreased the damage induced by oxygen stress. Thus, the Se-enriched C. utilis increased activities of GSH-Px, CAT and SOD, decreased MDA contents, resulted in much greater antioxidant capacity of broiler chickens than those of the control.

Thymus, spleen, and fabricius are important immune organs of broiler chickens. The development status and functions of these organs directly determine the chicken's immune level (Yang et al., 2016). The greater the immune organ index, the greater the chicken immunity level can be expected. In this study, no significant differences in the immune organ indices were found between the dietary supplement of Seenriched C. utilis and the control. However, this dietary supplement improved the levels of immunoglobulins in the serum of broiler chickens. The Se-enriched $C$. utilis resulted in the highest titers of $\lg G, \lg M$, and $\lg A$, showing much greater immunity function than those of the control. Organic Se and GSH can increase the numbers of phagocytic cells, promote the proliferation of lymphocytes, and improve the biosynthesis of immunoglobulin, which ultimately improve the immune function of animals (Spallholz et al., 1990).

Besides, other dietary supplements containing Se and/or GSH were also tested in this study. Both organic Se of Se-enriched $S$. cerevisiae and inorganic Se of $\mathrm{Na}_{2} \mathrm{SeO}_{3}$ supplemented in the diet increased Se contents in the whole blood and liver. The supplementation of C. utilis cells increased GSH contents in blood, liver, and breast meat of broiler chickens, which in turn decreased MDA contents in serum and tissues. As compared to the above supplements and the control, Se-enriched C. utilis is the most potential feed additive for Se supplementation to improve the antioxidant capacity and immune function of broiler chickens.

In summary, the effect of Se-enriched C. utilis and other Se and/or GSH dietary supplements in the diet of broiler chickens was investigated in this study. Based on Se distribution, activities of GSH-Px, CAT, and SOD, GSH and MDA contents, immune organ indices, and $\lg G, \lg M$, and $\lg A$ titers in the serum, Se-enriched C. utilis was shown to be a good dietary supplement candidate to improve antioxidant capacity, 
and immune functions of broiler chickens. This study not only indicated that the Se-enriched C. utilis was superior to other additives in the raising of broiler chickens but also expanded the potential applications of the selenized yeast in feed additives.

\section{ACKNOWLEDGEMENTS}

This work was supported by the National Natural Science Foundation of China (21506136), Suzhou Applied Fundamental Research Program (SNG201606), and a Project Funded by the Priority Academic Program Development of Jiangsu Higher Education Institutions.

\section{REFERENCES}

Arthur JR. The glutathione peroxidases. Cellular and Molecular Life Sciences 2000;57:1825-1835

Baltić MŽ, Dokmanović SM, Bašić M, Zenunović A, Mahmutović H. Effects of selenium yeast level in diet on carcass and meat quality, tissue selenium distribution and glutathione peroxidase activity in ducks. Animal Feed Science and Technology 2015;210:225-233.

Beck MA, Levander OA, Handy J. Selenium deficiency and viral infection. Journal of Nutrition 2003;133:1463S-1467S.

Boostani A, Sadeghi AA, Mousavi SN, Chamani M, Kashan N. Effects of organic, inorganic, and nano-Se on growth performance, antioxidant capacity, cellular and humoral immune responses in broiler chickens exposed to oxidative stress. Livestock Science 2015;178:330-336.

Burk RF. Selenium, an antioxidant nutrient. Nutrition in Clinical Care 2002;5:75-79.

Fairweather-Tait SJ, Bao Y, Broadley MR, Collings R, Ford D, Hesketh JE, et al. Selenium in human health and disease. Antioxidants and Redox Signaling 2011;14:1337-1383.

Food and Drug Administration. Food additive permitted in feed and drinking water of animals: selenium yeast. Federal Register 2000;65:3582335824 .

Galano A, Alvarezidaboy JR. Glutathione: mechanism and kinetics of its non-enzymatic defense action against free radicals. RSC Advances 2011;1:1763-1771

Gan F, Chen X, Liao SF, Lv C, Ren F, Ye G, et al. Selenium-enriched probiotics improve antioxidant status, immune function, and selenoprotein gene expression of piglets raised under high ambient temperature. Journal of Agricultural and Food Chemistry 2014;62:4502-4508.

Hoffmann PR, Berry MJ. The influence of selenium on immune responses. Molecular Nutrition and Food Research 2008;52:1273-1280.

Honikel KO. Reference methods for the assessment of physical characteristic of meat. Meat Science 1998;49:447-457.

Kieliszek M, Błażejak S. Selenium: significance, and outlook for supplementation. Nutrition 2013;29:713-718

Kieliszek M, Błażejak S, Gientka I, Bzducha-Wróbel A. Accumulation and metabolism of selenium by yeast cells. Applied Microbiology and Biotechnology 2015;99:5373-5382.

Kieliszek M, Blazejak S, Kurek E. Binding and conversion of selenium in Candida utilis ATCC 9950 yeasts in bioreactor culture. Molecules $2017 ; 22: 352$
Koh YH, Park YS, Takahashi M, Suzuki K, Taniguchi N. Aldehyde reductase gene expression by lipid peroxidation end products, MDA and HNE. Free Radical Research 2000;33:739-746.

Li JL, Zhang L, Yang ZY, Zhang ZY, Jiang Y, Gao F, et al. Effects of different selenium sources on growth performance, antioxidant capacity and meat quality of local Chinese Subei chickens. Biological Trace Element Research 2017;181:1-7.

Li Y, Wei G, Chen J. Glutathione: a review on biotechnological production. Applied Microbiology and Biotechnology 2004;66:233-242.

Nie M, Wei G, Shao N, Ge X. A novel strategy on the high-cell-density cultivation of Candida utilis for the enhanced production of glutathione. Korean Journal of Chemical Engineering 2010;27:1246-1251.

Phongpangan $\mathrm{P}$, Jung J, Anthony NB, Karnuah AB, Mulligan JH, Aggrey SE, et al. Quality attributes in breast muscle from broilers of an Arkansas randombred line varying in growth rate. Poultry Science 2014;93:187193.

Rayman MP. The importance of selenium to human health. Lancet 2000;356:233-241.

Rayman MP. Selenium in cancer prevention: a review of the evidence and mechanism of action. Proceedings of the Nutrition Society 2005;64:527-542

Schrauzer GN. Selenium yeast: composition, quality, analysis, and safety. Pure and Applied Chemistry 2006;78:105-109.

Shi L, Ren Y, Zhang C, Yue W, Lei F. Effects of maternal dietary selenium (Se-enriched yeast) on growth performance, antioxidant status and haemato-biochemical parameters of their male kids in Taihang black goats. Animal Feed Science and Technology 2017;231:67-75.

Spallholz JE, Boylan LM, Larsen HS. Advance in understanding selenium's role in the immune system. Annals of the New York Academy of Sciences 1990;587:123-139.

Surai PF, Fisinin VI. Selenium in poultry breeder nutrition: an update. Animal Feed Science and Technology 2014;191:1-15

Tapiero H, Townsend DM, Tew KD. The antioxidant role of selenium and seleno-compounds. Biomedicine and Pharmacotherapy 2003;57:134144

Wang D, Yang B, Wei G, Liu Z, Wang C. Efficient preparation of selenium/ glutathione-enriched Candida utilis and its biological effects on rats. Biological Trace Element Research 2012;150:249-257.

Wang $\mathrm{YB}, \mathrm{Xu} \mathrm{BH}$. Effect of different selenium source (sodium selenite and selenium yeast) on broiler chickens. Animal Feed Science and Technology 2008;144:306-314.

Yang B, Wang D, Wei G, Liu Z, Ge X. Selenium-enriched Candida utilis: efficient preparation with L-methionine and antioxidant capacity in rats. Journal of Trace Elements in Medicine and Biology 2013;27:7-11.

Yang Z, Liu C, Liu C, Teng X, Li S. Selenium deficiency mainly influences antioxidant selenoproteins expression in broiler immune organs. Biological Trace Element Research 2016;172:209-221.

Yang Z, Liu C, Zheng W, Teng X, Li S. The functions of antioxidants and heat shock proteins are altered in the immune organs of selenium-deficient broiler chickens. Biological Trace Element Research 2016;169:341-351.

Yin H, Fan G, Gu Z. Optimization of culture parameters of selenium-enriched yeast (Saccharomyces cerevisiae) by response surface methodology (RSM). LWT-Food Science and Technology 2010;43:666-669.

Zhang L, Liu XR, Liu JZ, An XP, Zhou ZQ, Cao BY, et al. Supplemented organic and inorganic selenium affects milk performance and selenium concentration in milk and tissues in the Guanzhong dairy goat. Biological Trace Element Research 2018;183:254-260. 
